\title{
Nutrition education for illiterate children in southern Madagascar - addressing their needs, perceptions and capabilities
}

\author{
Johanna Mahr ${ }^{1, *}$, Marzella Wuestefeld ${ }^{1}$, Joep ten Haaf ${ }^{2}$ and Michael B Krawinkel ${ }^{1, *}$ \\ ${ }^{1}$ Institute of Nutritional Science, Justus-Liebig-University Giessen, Wilhelmstrasse 20, D-35392 Giessen, \\ Germany: ${ }^{2}$ Consultant
}

Submitted 23 November 2003: Accepted 29 September 2004

\begin{abstract}
Objective: A Knowledge, Attitudes and Practices (KAP) study was conducted in three villages of Bekily District in southern Madagascar prior to the implementation of a health education programme with children. The participatory learning concept of the Child-to-Child approach was followed to involve the children in the planning and implementation of the programme, which was covered by the German Agency for Technical Cooperation.

Design: To this effect, qualitative research methods such as Participatory Learning and Action techniques (focus group discussions, mapping and matrix ranking, etc.) were applied.

Subjects: The survey was conducted between August and December 1999. It involved a total of 55 school-aged children (6-14 years) along with 21 mothers and 34 fathers, representing different ethnic groups and educational backgrounds.

Results: The results show that children's KAP related to health and nutrition strongly reflect those of adults. They are not aware of a possible link between bad hygiene and the occurrence of diseases. According to them, diarrhoea or malaria is caused by consuming too large amounts of certain foods. Even if they know about certain elementary hygiene behaviours, they do not practise this in their everyday life.

Conclusion: A major objective of the health education programme for children should be to tackle the discrepancy between hygiene-related knowledge and behaviour. Through the participatory study approach the children revealed their ability to contribute to the programme development. In using appropriate communication channels, the Child-to-Child health education programme is expected to influence the health behaviours of both adults and children. The health education programme should be combined with a literacy programme to address the children's desire to learn reading and writing.
\end{abstract}

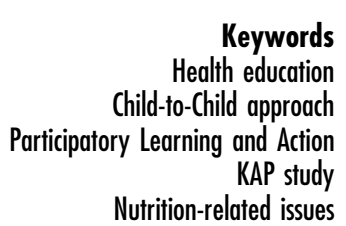

Keywords Health education Learning and Action Nutrition-related issues
Health education placed in the broader perspective of life skills training programmes at schools has a positive influence on health. However, it does not reach children who are not going to school. In Bekily District in southern Madagascar, $85 \%$ of children aged 6-14 years never go to school $^{1}$. In the absence of a functioning education programme in schools, the children depend on the education provided by their family and community. This education focuses on imparting traditional values and prepares the child for the role it has to play in this society by scrupulously following in the footsteps of the ancestors. However, the needs, rights, responsibilities, views and interests of young and old, male and female, are not synonymous.

Children represent important links in the traditional social network, making their own social, economic and cultural contributions to society. Children are still acquiring values and ways of thinking and behaving.
The Integrated Food and Nutrition Security Programme of the German Agency for Technical Cooperation in southern Madagascar decided to target not only adults but also school-aged children: health and nutrition education focusing on children promises sustainable changes in dietary behaviour and health care.

The study was designed against the backdrop of implementing a health and nutrition education programme by using original communication methods of the children. Its overall objective was to involve children in participatory interactions to get a better understanding of their lives and their roles in the family and community, as well as their wishes and capabilities. The specific objective was to explore communication channels through which the health and nutrition perceptions of children can be fed into policy and programming. Through communication channels such as games and songs, health information can eventually be passed on from child to child or from child to adult. These 
objectives require a participatory research approach, which involves the children in developing and implementing the programme.

The participatory learning concept of the Child-to-Child approach builds on the tradition that older children in Madagascar are urged to become responsible contributors to the family at a very early age and play an important role in the rearing of their younger siblings. The aim is to give children the opportunity to become partners in primary health care by imparting knowledge and skills enabling them to protect their health, that of their siblings and the community $^{2,3}$. Through child-centred Participatory Learning and Action (PLA) techniques, the children are actively involved in programme development.

\section{Subjects and methods}

\section{Study area}

Research was conducted in Bekily District in southern Madagascar, an area of $5274 \mathrm{~km}^{2}$ in which some 120000 people live. Of these $66.5 \%$ are Antandroy, an ethnic group of pastoralists who have now settled down in the area, and $22 \%$ are Antanosy, who are specialised in rice production. The remaining population consists of small groups of migrants from other areas of Madagascar. In 1998 there were 37 public primary schools, which had enrolled 2757 children, and 15 private primary schools with 1202 children enrolled. The public health system is even less developed. In 1997 there was a hospital in Bekily and 13 rural health posts in the district, which were served by one physician, eight midwives, 12 nurses and 10 'aides sanitaires ${ }^{, 4}$.

Three 'fokontany' (villages) were selected for this study: Ambararata Toby, a Tandroy village, Anaviavy, a Tanosy village, and Bevale where Antandroy and Antanosy cohabit. Ambararata Toby and Anaviavy were chosen to compare the Knowledge, Attitudes and Practices (KAP) of children of different cultural background, whereas Bevale was chosen because of the presence of a primary school and hence the possibility to study the influence of formal education.

\section{Study population}

The study in the selected villages took place from August to December 1999. Each village was visited one day every week. Longer stays for two consecutive days and nights were arranged so that the facilitators could observe the daily life in the village and discuss with other inhabitants. A total of 55 school-aged children (6-14 years) along with 21 mothers and 34 fathers, representing different ethnic groups and educational backgrounds, were involved in the study. In Ambararata Toby an average of nine children participated, in Anaviavy 18 and in Bevala 32. The latter number of participants was very large, but the children refused to be divided into two smaller groups. In all three villages an average of seven mothers and 12 fathers participated in group discussions, which were conducted after the sessions with the children. The remarks made by boys and girls were recorded separately to enable study of the effect of gender on children's KAP.

\section{Study metbods}

The Child-to-Child approach is a step-by-step educational process based on the theories of active learning and empowerment education. The methodology consists of participatory techniques. During the present study the first three steps of the approach were applied. First, the children and their facilitators identified a priority health or nutrition issue and afterwards they carried out activities to define the issue and to increase their understanding of it. In a second step they gathered information in the community to find out more about the issue. Finally they discussed the results and proposed actions to do something about $\mathrm{it}^{5}$. The steps, which follow these initial steps of taking action, evaluate and improve the action, were to be carried out during the implementation of the health education programme. The flexible character of PLA techniques allows for their adaptation to specific target groups and cultural settings ${ }^{6}$. As most of the children in the study area are illiterate, oral and visual PLA techniques were applied using designs and symbols. The techniques concentrated on learning with and from children about their knowledge, attitude and behaviour with respect to health and nutrition-related issues in a holistic manner, covering cultural social and educational aspects. The following topics for research were proposed:

1. nutrition;

2. health, aetiology of diseases, prevention and treatment of sickness;

3. hygiene, sanitation and hygienic behaviour;

4. social life, education methods and children's daily work and games; and

5. communication channels - songs, dances, storytelling, drama.

Table 1 gives an overview of the PLA techniques used ${ }^{7,8}$. Each technique was accompanied by group discussions and a semi-structured interview guide was used. The information gathered was complemented by focus group discussions with fathers or mothers and semi-structured interviews with individual children and key informants. Discussions with the mothers concentrated on nutrition, health and the daily life, whereas discussions with the fathers focused on social aspects and education.

Three women and one man who conducted the fieldwork in the three villages assisted the reporting author. They were Antandroy or Antanosy and as such familiar with local languages, customs and habits. Prior to the fieldwork they were introduced to the Child-to-Child approach and intensively trained in the use of PLA techniques. Two teams of two persons were formed: one guiding the process as moderator, the other recording the results. 
Table 1 Participatory Learning and Action techniques used to obtain children's knowledge, attitudes and practices of health and nutrition-related topics

\begin{tabular}{|c|c|}
\hline Method & Type of information obtained \\
\hline Individual and key-person interviews & $\begin{array}{l}\text { Personal and detailed examination of a child's conception } \\
\text { Teacher's viewpoint of children's health knowledge and behaviour }\end{array}$ \\
\hline Daily routine diagram & Children's daily activities \\
\hline Matrix ranking & Children's preferences and problems related to food, daily activities and social life \\
\hline Causality diagram & Children's perception on causes of most frequent diseases \\
\hline Participatory mapping & Children's awareness of the use of available water sources \\
\hline
\end{tabular}

\section{Data analysis}

The results of the various sessions were immediately written down in Malagasy and translated afterwards. The qualitative data were analysed in collaboration with the fieldworkers during a 2-month period immediately after the 5 months of data collection. Chambers recommends verifying the analysed results of PLA techniques with the participants 9 . Experiences of other projects show that school-aged children are too young to do $\mathrm{so}^{10}$. Results were validated and possible misinterpretations minimised by observing the population's practices, by comparing results from a variety of PLA techniques (triangulation) and by analysing the data in collaboration with people of different professions and socio-cultural backgrounds familiar with the local situation for years, as well as cross-checking the data with other regional studies ${ }^{6,11}$. The fieldworkers of the present study confirmed Johnson's experience of children giving frank and spontaneous answers, which underlines the validity of the data ${ }^{12}$.

\section{Results}

\section{Children's perception of nutrition}

During brainstorming on the topic of nutrition the children talked primarily about food production and cookery. Secondarily, specific food items were mentioned (Fig. 1). They ranked common food items according to their preferences, which shows their perception of food as a cause of disease.

1. Rice and meat are preferred as these foods taste good and seldom cause diseases.

2. Maize, sweet potato and milk are considered to be good food items, but also may cause diseases such as stomach pains and diarrhoea.

3. Cassava and leafy vegetables are not appreciated and thought to often cause diseases.

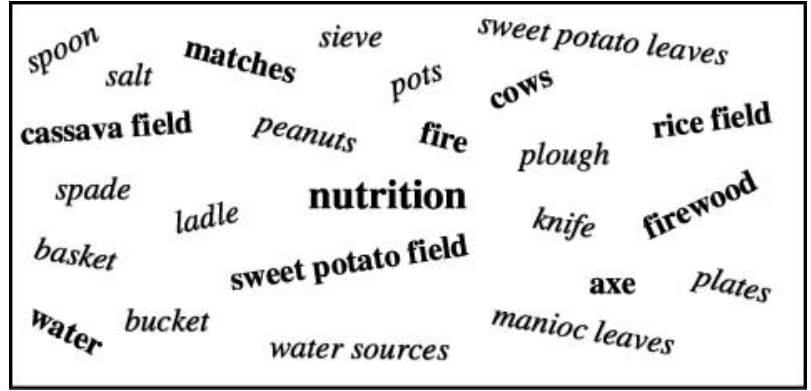

Fig. 1 Brainstorming on the topic of nutrition (Ambararata Toby village, August 1999); boys' answers and girls' answers

The children enjoy eating mangoes and other fruits like bananas and cactus fruits because of their sweet taste. During the pre-harvest hunger season ('kerempaosa') they eat fruits in large quantities. Unripe and ripe mangoes are the first fruits available in November to January followed by the cactus fruit ('raketa'). Eating more or less ripe fruits may cause stomach pains and diarrhoea. Nevertheless, the children like to eat them. They think that the consumption of large quantities of fruits causes disease: mangoes cause malaria and cactus fruits constipation. As the two events of eating mangoes and getting malaria happen around the same time, they think there is a causal link.

Vegetables eaten are mainly leaves of sweet potato ('ravimbageda'), pumpkin ('taboara') and cassava ('ravitoto'). The children do not appreciate these vegetables when simply boiled with water and salt, as they cause stomach ache and diarrhoea according to them. However, when peanuts, meat or tomato are added to the preparation children like to eat it. Both adults and children suspect that salt causes sicknesses like stomach ache, diarrhoea and vomiting when used too much or wrongly. Its use is dictated by a strictly respected taboo, which forbids people to bring salt in contact with milk. 


\section{Children's perception of bealth}

The children ranked the most common diseases according to frequency, seriousness and how much it affects their ability to work or play as follows: malaria, headache, stomach ache and diarrhoea. Differing ideas about the causality of diseases abound among the children. In the causality diagram, children mentioned as causes of diarrhoea the consumption of large amounts of tamarind fruits, meat and salted vegetables and the occurrence of intestinal parasites (Fig. 2). Some children talked about dirty fingernails causing stomach ache because dirt gets mixed into the meal. Eating dirty and old food or using not boiled water from natural unprotected wells or ponds were also quoted as a cause of stomach ache. As a primary cause of illness they see the wrath of the ancestors or the spirits of other dead persons aroused as a result of misbehaviour like eating too much or showing disrespect for a person, law or custom.

\section{Children's perception of bygiene}

The process of participatory mapping revealed children's awareness of the importance of keeping drinking water sources separate from other water sources used for washing, bathing and livestock. The children assigned different functions to different local water sources (Fig. 3). Some sources are permanent whereas others are only seasonal. Wherever possible they have a special source for drinking water, which provides water for the kitchen, to wash dishes and to cook. Other sources are used to water the animals, to wash the clothes and to take a bath. Nevertheless, the children say that if they are thirsty they may drink from the nearest source without paying respect to the different assignments of the water sources. Cattle drinking from or bathing in the same pond do not disturb them, since cattle are not considered a source of pollution. On the contrary, cattle are a source of well-being.

In assessing children's understanding of hygiene, boys talk about bathing in the pond and washing clothes, whereas girls talk about cleaning the house, plates and foods. They consider washing hands before meals as unimportant and talk about using soap mainly for washing

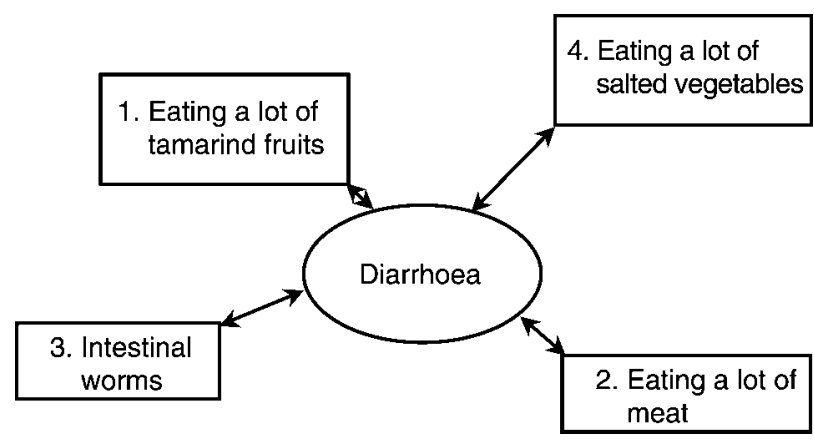

Fig. 2 Causality diagram for diarrhoea (Bevala village, September 1999); shorter arrows represent what children believe to be stronger causes of diarrhoea

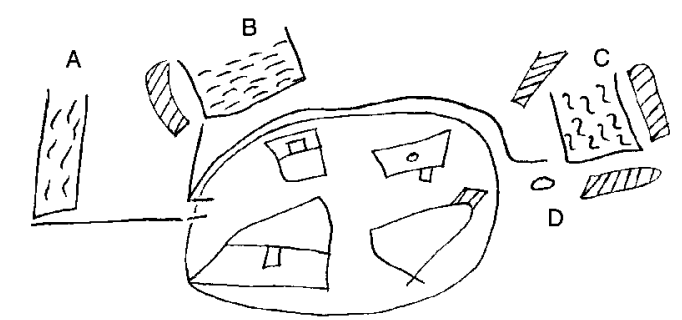

Index of uses for water

A (Antsoko pond): washing dishes, bathing and watering cows

B (Andabolava pond): washing dishes, bathing, watering cows, drinking

C (Akarefo pond): watering gardens

D (natural well): drinking and cooking, washing dishes

Fig. 3 Participatory mapping of local water sources and their uses (Ambararata Toby village, September 1999)

themselves in the pond before going to a weekly market or a cultural ceremony. Cleanness is appreciated as it increases someone's physical attractiveness.

\section{Children's perception of their role in everyday life}

From a very early age the gender difference between women's and men's roles is internalised, as the matrix ranking exercise of children's occupations shows (Fig. 4). Typically, young boys are expected to be responsible for the cattle, sheep and goats of the family and to assist their fathers with agricultural tasks. They like herding cattle because this allows them to play, to drink milk and to take care of the family's wealth. Young girls have to fetch water, are sent to the garden to get some vegetables, assist in cooking, wash up and sweep the house. From the age of 8 years onward girls start taking care of their younger siblings aged 6 months and older. They play the role of surrogate mother and are responsible for their hygiene behaviour: washing their cloths, bathing them and teaching them to fetch water and clean the house. Older boys teach younger siblings how to accomplish their daily tasks like herding cattle.

\section{Children's games}

Children's preferred games portray their daily activities: the boys' game 'tsikianombe' consists of reproducing scenes of cattle raising and herding with small figures modelled in clay; the girls' game 'tsikintrano' is an imitation of the household chores. When the children are older they participate in wrestling exercises (' $r i n g a$ ') which take place regularly when the moon is full: girls sing, dance, beat the drums or clap to encourage the boys to participate. The children often express their desire to learn to read and write, an issue that their parents also bring up frequently.

\section{Views and opinions of the parents concerning their children}

Fathers emphasise the need for children to learn the cultural practices, taboos and family relations. Children 


\begin{tabular}{|l|c|c|c|c|c|c|c|}
\hline & $\begin{array}{c}\text { Watch } \\
\text { cows }\end{array}$ & $\begin{array}{c}\text { Get } \\
\text { water }\end{array}$ & $\begin{array}{c}\text { Husk } \\
\text { rice }\end{array}$ & Cook & $\begin{array}{c}\text { Collect } \\
\text { firewood }\end{array}$ & Field work & $\begin{array}{c}\text { Gather } \\
\text { vegetables }\end{array}$ \\
\hline $\begin{array}{l}\text { Lambo } \\
\text { (boy) }\end{array}$ & $\bullet \bullet \bullet$ & & & & & $\bullet \bullet$ & \\
\hline $\begin{array}{l}\text { Pauline } \\
\text { (girl) }\end{array}$ & & $\bullet \bullet$ & $\bullet$ & $\bullet \bullet \bullet$ & & & $\bullet$ \\
\hline
\end{tabular}

Fig. 4 Example of matrix ranking for two children's frequency of daily activities (Ambararata Toby village, August 1999); number of dots in a field indicates the priority of the activity

should be trained to work hard and readily in house or farm from 5 years onwards. The parents consider storytelling, using proverbs, fables and discussions appropriate methods for explaining to their children how to behave. Children have to show respect and obedience in their behaviour towards adults. Nevertheless, fathers listen to children's ideas and advice and accept it if it is useful. Children as young as 6 years are responsible for their own cleanliness and older children are responsible for younger siblings.

\section{Discussion}

In studying the nutrition-related knowledge, attitudes and practices of mainly illiterate school-aged children in southern Madagascar, a discrepancy between their knowledge and behaviour emerges. The sample size of 55 children of the present study is too small to draw statistically secure conclusions. However, the results are sufficiently homogeneous to allow valuable insights with respect to knowledge, attitudes and practices.

The children mentioned the consumption of large amounts of green mangoes and salted vegetables as one cause of diarrhoea, an attitude that is known from other countries as well ${ }^{13,14}$. Nevertheless, the children in the Bekily project region eat these foods in large quantities. They are acquainted with the importance of elementary hygiene, like clean fingernails to prevent stomach ache and the rule of using different water sources for different uses, but they do not practise it in their daily lives. A KAP study in the neighbouring area conducted by the United Nations Children's Fund also observed these behaviours and attitudes among interviewed women ${ }^{15}$.

When addressing the gap between health-related knowledge and practices, the question arises of what motivates people to behave in the way they do. What does their knowledge about a certain health topic actually mean? ${ }^{16}$ What is the explanatory role of nutrition knowledge in changing nutrition behaviours?

Nutrition knowledge is a necessary but not sufficient factor for changes in nutrition behaviours ${ }^{17}$. Nutrition behaviours are influenced by a number of factors. The educational process has to be viewed within the framework of the entire social organisation, as cultural beliefs and norms dictate health and nutrition behaviours.
Nutrition education programmes have to be designed with sensitivity to cultural practices, values and beliefs ${ }^{18}$. The best way to achieve this is to implement programmes using a participatory approach that actively involves the target group and takes into account their understanding of health and nutrition ${ }^{19}$.

Comparing the results obtained in the three villages of the study, no significant differences were found in KAP of Tandroy and Tanosy children. Neither did boys' and girls' KAP differ. The presence of a school in Bevala does not seem to have significant relevance. All three villages are traditional rural settings in which family life, rules of moral behaviour, education, livelihood and the traditional belief system are more or less identical. The population is proud of its ancestry, culture and mode of living. It is not likely to promote foreign customs ${ }^{4}$. The best way to live is the way the ancestors have ordained ${ }^{20}$. This adage applies also to health and nutrition behaviour.

The causes of illness are far more behavioural than biological: the malefic actions of other people or the wrath of ancestors are invoked as the main causal factors by the children. The children's attitude reflects the aetiological theories of illness in their society. Even if there is much speculation about the causes of sicknesses, the latter are considered a secret only known to healers or medical doctors. In particular, in the vicinity of well-functioning basic health centres or hospitals, there is a high rate of dual usage of modern and traditional health-care resources. There is practically no use of the biological germ theory to explain sickness - the view of modern medicine because germs are invisible. Aetiology assumptions have repercussions on behaviour: many health problems such as sores and diarrhoea occur that could be prevented by practising better hygiene habits ${ }^{21-24}$. Other studies also underline the lack of good hygiene practices in the population of Bekily ${ }^{15,25}$. A recommended major goal of the nutrition education programme for children is to improve the population's hygiene behaviour. Educational interventions need to be combined with those improving access to clean drinking water, which is provided for only $6 \%$ of households ${ }^{26,27}$.

Many approaches and theories have been discussed to bridge the gap between nutrition-related knowledge and behaviour $^{28}$. Recent reviews have noted that behavioural theory-based nutrition education programmes are more 
successful at achieving nutrition and health behaviour change than knowledge-based programmes. These programmes target personal, behavioural or environmental factors that influence the behaviour and apply theory-based strategies to influence those factors. The goal-setting strategy is frequently used in nutrition education programmes to enhance the behaviour change process $^{29}$; its steps of establishing a goal, adopting a goal-directed activity and self-monitoring are similar to the steps of the Child-to-Child approach. According to the goal-setting strategy, the children in southern Madagascar still have to recognise the need for change. Imparting knowledge plays an important role in developing a healthy awareness of how to profit from improved hygiene, like washing hands, using soap and drinking clean water ${ }^{17}$. Through the Child-to-Child approach the children learn by experiencing and discovering by themselves, which helps to put the acquired knowledge about improved hygiene behaviour into practice p $^{3,30}$.

The results of the study confirm the children's capacity to act as health agents in their community and family, as well as the cultural acceptance of the Child-to-Child approach. The capacity arises because older children teach younger siblings, girls are responsible for younger children's hygiene behaviour and adults may accept advice given by children if it is useful. Through critical thinking, information gathering in the community and participating in child-centred PLA techniques, the illiterate children in the project region actively contributed to designing the health education programme by applying the first three steps of the Child-to-Child approach. In accordance with to a rights-based approach to programming, the Child-to-Child approach is based on Article 12 of the Convention on the Rights of the Child, which endorses the right of the child to participate ${ }^{31}$.

To enable the children to act as health agents, communication methods need be applied that are familiar to them and adapted to their abilities and interests as well as cultural and social environments ${ }^{32}$. In southern Madagascar children's favourite games are 'tsikianombe' and 'tsikintrano', which show their daily tasks in role plays $^{33}$. These games are excellent methods to pass on messages to other children and the community when adding specific health messages. Messages should focus on solutions rather than problems; they should concentrate not only on what to do but why to do $\mathrm{it}^{18}$. Other useful devices are singing and dancing, which are the children's main leisure activities and a valuable means for them to express their views and ideas ${ }^{34}$. Developing new songs including specific health messages is a pleasure for them. To pass on traditions from one generation to another the people of southern Madagascar use stories, proverbs and fables, which can be used effectively in health education. The study revealed that child-centred PLA techniques, such as group discussion, surveys, mapping, ranking and drawing, are excellent tools to raise awareness of specific health topics ${ }^{35}$. The illiterate children in southern Madagascar enjoy these techniques as new games.

For the nutrition education programme in southern Madagascar, it is recommended to exploit children's motivation and desire to learn to read and write. The need to address illiteracy is underlined by the fact that $89.7 \%$ of children older than 10 years are illiterate in the region ${ }^{1}$. As well as being little developed, the school education system encounters much distrust as it is considered an instrument of discontinuity: children tend to become alienated from the traditional way of life and may face problems of cultural and social integration ${ }^{36}$. Under the present circumstances marked by a strong increase in population, school education will become more important and the parents want their children to learn reading and writing. The functional literacy approach developed by Paulo Freire teaches reading and writing by focusing on a specific topic concerning the participants' daily lives ${ }^{37}$. Health messages on hygiene could be communicated to the children while teaching them to read and write, as part of the participatory learning concept of the Child-to-Child approach.

\section{References}

1 Institut National de la Statistique (INSTAT). Recensement général de la population et de l'habitat, éducation, rapport d'analyse, Vol. 2. Tome II: Antananarivo: INSTAT, 1997.

2 Bailey D, Hawes H, Bonati G. Child-to-Child: A Resource Book. Part 1: Implementing the Child-to-Child Approach. London: Child-to-Child Trust, 1992.

3 Lansdown R. Child-to-Child. Dialogue on Diarrboea 1995; (60): 6.

4 Wüstefeld M. Bekily, pays des tamariniers. Quelques aspects de sécurité alimentaire dans le Sud de Madagascar. Antananarivo: Tsigika, 2001

5 Pridmore P, Stephens D. Children as Partners for Health, A Critical Review of the Child-to-Child Approach. London: Library of Congress, 2000.

6 Pretty JN, Guijt I, Scoones I, Thompson J. A Trainer's Guide for Participatory Learning and Action. London: International Institute for Environment and Development, 1995.

7 Theis J, Grady H. Participatory Rapid Appraisal for Community Development. London: International Institute for Environment and Development/Save the Children Foundation, 1991.

8 Institute of Development Studies (IDS). Relaxed and Participatory Appraisal Notes on Practical Approaches and Methods. Notes for participants in PRA Familiarisation Workshops in the second half of 1999. London: IDS, 1999.

9 Chambers R. Rural Appraisal: Rapid, Relaxed and Participatory. IDS Discussion Paper No. 311. London: Institute of Development Studies, 1992.

10 Gordon G. Introduction: how to, the process. In: Johnson V, Ivan-Smith E, Gordon G, Pirdmore P, Scott P, eds. Stepping Forward, Children and Young People's Participation in the Development Process. London: Intermediate Technology Publications, 1998; 66-9.

11 Schönhuth M, Kievelitz U. Participatory Learning Approaches, Rapid Rural Appraisal, Participatory Appraisal, 
An Introductory Guide. Eschborn: Gesellschaft für Technische Zusammenarbeit/TZ-Verlag, 1994.

12 Johnson V. Starting a dialogue on children's participation. In: International Institute for Environment and Development (IIED), ed. Special Issue on Children's Participation. PLA Note 25. London: IIED, 1996; 30-5.

13 Pebley A, Hurtado E, Goldman N. Beliefs about children's illness. Journal of Biosocial Science 1999; 31(2): 195-219.

14 Khamis T. Health Interests, Knowledge and Needs of Pakistani Primary School Children. Karachi: Age Khan University, 1997.

15 United Nations Children's Fund (UNICEF). Rapport d'enquête CAP et FGD Projet UNICEF. Points d'eau positif dans le Sud de Madagascar. Antanimora-Sud: UNICEF, 1999.

16 Antia BE, Omotara BA, Rabasa AI, Addy EO, Tomfafi OAA, Anaso CC. More reliable data for diarrhoeal intervention programmes: rethinking on knowledge, attitude and practice studies. Journal of Health, Population, and Nutrition 2003; 21(2): 127-41.

17 Worsley A. Nutrition knowledge and food consumption: can nutrition knowledge change food behaviour. Asia Pacific Journal of Clinical Nutrition 2002; 11: 579-85.

18 Yoddumnern-Attig B, Atting GA, Kanungsukkasem U. Incorporating explanatory models in planning nutrition education programmes in Thailand. Nutrition and Health 1992; 8(1): 17-31

19 Bradley S. Participatory learning. Dialogue on Diarrhoea 1995; (60): 2.

20 Benelo F. Variétés des sacrifices traditionnels dans l'Androy. In: Gueunier NJ, Raharinjanahary S, eds. Raki-pandinihana, études offertes au professeur Rajaona. Fianarantsoa: Le Ministère de l'Enseignement Supérieur, 2000; 257-69.

21 Goldman N, Perbley AR, Beckett M. Diffusion of ideas about personal hygiene and contamination in poor countries: evidence from Guatemala. Social Science \& Medicine 2001; 52(1): 53-69.

22 Khan MU. Interruption of shigellosis by hand washing. Transactions of the Royal Society of Tropical Medicine and Hygiene 1982; 76: 164-8.

23 Clemens JD, Stanton BF. An educational intervention for altering water-sanitation behaviours to reduce childhood diarrhoea in urban Bangladesh, 1. Application of the casecontrol method for development of an intervention. American Journal of Epidemiology 1987; 125: 284-91.

24 Gorter AC, Sandiford P, Pauw J, Morales P, Perez RM, Alberts $\mathrm{H}$. Hygiene behaviour in rural Nicaragua in relation to diarrhoea. International Journal of Epidemiology 1998; 27(6): 1090-100.

25 Institut National de la Statistique/Demographic and Health Surveys. Enquête démographique et de santé (EDS) 1997, Madagascar. Calverton, MD: Macro International, 1998.

26 Wüstefeld M. Enquête de base sur la situation de la sécurité alimentaire dans la région de Bekily, Sud de Madagascar. Bekily: Coopération Allemande au Développement, 1998.

27 Andrien M, Beghin I. Nutrition education or managing social communication for nutrition? Promoting Education 1993 $25-32$.

28 Elder JP, Ayala GX, Harris S. Theories and intervention approaches to health-behavior change in primary care. American Journal of Preventive Medicine 1999; 17(4): 275-84.

29 Cullen KW, Baranowski T, Smith SP. Using goal setting as a strategy for dietary behaviour change. Journal of the American Dietetic Association 2001; 101(5): 562-6.

30 Phinney R, Evans J. From child to child: children as communicators. Development Communication Report 1993 (78): 7-9.

31 Otaala B. Children's participation for research and programming in education, health and community development: selected experiences in Africa. In: Johnson V, Ivab-Smith E, Gordon G, Pirdmore P, Scott P, eds. Stepping Forward, Children and Young People's Participation in the Development Process. London: Intermediate Technology Publications, 1998; 135-42.

32 Hart R. The developing capacities of children to participate. In: Johnson V, Ivan-Smith E, Gordon G, Pirdmore P, Scott P, eds. Stepping Forward, Children and Young People's Participation in the Development Process. London: Intermediate Technology Publications, 1998; 27-31.

33 Ravololomanga B. Etre femme et mère à Madagascar Tanala d'Infanadana. Paris: L'Harmattan, 1992.

34 Johnson J, Hill J, Ivan-Smith E. Listening to Smaller Voices: Children in an Environment of Change. London: ActionAid, 1995.

35 Duchscherer D, Duchscherer C, Namgyal R, Iqbal M. Child participation in practice: SCF (Save the Children Fund) experiences in programming. In: Institute of Development Studies (IDS), ed. PRA with Children. PRA Topic Pack. London: IDS, 1996.

36 Roubaud F, Coury D. Le travail des enfants à Madagascar. Genève: Un Etat des Lieux, 1997.

37 Freire P. Pedagogy of Hope. New York: Continuum, 1994. 